\title{
Distance Learning Challenges in Translation Teaching: Mediation Competence Development
}

\author{
Lyudmila Enbaeva ${ }^{1,{ }^{*}}$ and Nina Plastinina ${ }^{2}$ \\ ${ }^{1}$ Perm State Pedagogical-Humanitarian University, Ulitsa Sibirskaya, 24, 614045 Perm, Russia \\ ${ }^{2}$ Nizhnevartovsk State University, Ulitsa Lenina, 56, 628600 Nizhnevartovsk, Russia
}

\begin{abstract}
In recent years the COVID pandemic has influenced education significantly. The pace of digital transformation is very fast and requires a change of mindset. Translators or cross-language mediators have to work at the focal point of various information transfer processes. We think that a digital mindset of a future translator can be created by re-contextualising classroom communication reality with online teaching tools that will ensure synchronous and asynchronous studies. The challenges of online resources variety can be responded to by classifying them according to L2 communicative competence and translation competence structural components. Thus the choice of sources can be narrowed down according to specific teaching objectives. The research proposes a classification of online resources for mediation competence development which is a communicative competence component according to CEFR. Classification categories include online teaching tools that can help develop (1) skills of mediating concepts, texts, communication; (2) strategies of explaining new concepts and strategies of text simplification. The classification is used to work out a few sample activities for an L2 course within translation curriculum. It is assumed that the classification and sample activities will help teachers be more flexible facing distance learning challenges in translation teaching.
\end{abstract}

\section{Introduction}

In the uncertainty caused by the COVID pandemic, education has changed dramatically with a profound shift towards distance learning. Moving instruction online proved to be a problem complicated by such factors as digitization of information and communication, digital divide, online sources variety to name a few. The development of professional translation competences requires undivided attention to communication schemes changes. Another challenge is to overcome the digital divide, the answer to which is efficient use of online sources variety and combination of online and offline remote learning.

Over the past decade, the digitization of information and communication has brought about considerable changes in the ideology of communication schemes. The sets of beliefs

\footnotetext{
* Corresponding author: 1.v.enbaeva@gmail.com
} 
and practices as regards information and communication are revised in different domains. In the sphere of media this trend has provoked a wide discussion among scholars to highlight and cognate different (social, cultural, political, infrastructural) dimensions of the digital platforms phenomenon [1-14]. There is a vibrant academic debate about common dualism between 'online' and 'offline' as well as 'public sphere' and 'public space', about an exploration of publicness and processes of information circulation across digital and physical spaces [17]. It is quite fair to mention that nowadays publics is expressed through concepts like 'networked publics', 'hashtag publics', or notions which describe processes of information circulation such as 'virality', 'shareability', and 'spreadability'. We draw on this discussion to assume that the concept of a digital platform is multidimensional, to note the pace of digital transformation of communication, to stress the importance of a digital mindset for a future language worker.

Professional training of a future language worker - cross-linguistic mediator or translator should not only develop professional competences but also make instruction answer the current trends for remote learning and digital transformation of communication. There are multiple distance learning solutions that help teachers of different disciplines create a learning environment accessible online for synchronous and asynchronous teaching and learning. UNESCO has offered a list of educational online resources where categorizing is based on distance learning needs [7]. G. Motteram collected a number of case studies on innovative learning technologies and structured the monograph according to the learning aims and teaching contexts of primary education, secondary education, general adult language education, English for Specific Purposes and Business English, Academic English [10]. The present research pinpoints the need for classification that would narrow the choice of sources according to specific teaching objectives. This can facilitate the process of creating courses for remote learning. It seems especially valuable for crosslanguage mediation and translation courses which have to form general translation competencies and provide real translation or mediation situations. These educational programs can also incorporate simulation projects and internships in the field of translation [12] or professional community integration schemes involving translation and interpretation associations membership, contests participation or career advancement schemes [16]. If we respond to the challenges of teachers' task to build up distant courses within a short time limit confronted by online sources multiplicity, they can prove a powerful tool to promote cross-language mediation and eventually to undergird and sustain international collaboration as web-based learning has a high potential to open up ways for wider professional community integration.

\section{Problem Statement and Research Method}

Cognitive linguistics postulates the necessity of an all-embracing stance towards the mediation and translation process predetermined by the pivotal role of a mediator/translator/interpreter and their cognitive processes. In this respect we align with the anthropocentric paradigm of scientific knowledge that advocates the centrality of people's mental activity for the research in human-related spheres. Thus we state that mediator/translator/interpreter training requires simultaneous development of L2 communicative competence and translation/interpretation competence. This is a complex task which can be solved differently: (1) by means of incorporating L2 communicative competence into translation competence structure, or (2) by way of including mediation skills development into language education. The PACTE group followed the first option and defined translation competence as the underlying system of knowledge required to translate. They propose that translation competence: (a) is expert knowledge; (b) is predominantly procedural; (c) comprises different inter-related subcompetences; and (d) 
includes a strategic component. Sub-competences include six: bilingual, extra-linguistic, translation theory knowledge, instrumental, strategic, psycho-physiological [2]. The second approach is evident in mediation competence development as constituent of communicative competence. Council of Europe language policymakers have recently included mediation competence descriptors into the Common European Framework of Reference for Languages [4]. Both approaches admit that translators or cross-cultural mediators have to work at the focal point of various information transfer processes. Contemporary education has to bring professional training closer to actual profession-related situations where media platforms are both helpful and challenging. On the one hand, a teacher can create the necessary language landscape by re-contextualising classroom language reality adding fragments of new media communication (live streaming videos, interviews, online discussions, videoconferencing, etc.). As a result, students face real life communicative situation and solve profession-related tasks getting first-hand experience. On the other hand, it can be challenging due to the variety of media platforms, online resources, information and communication technologies. The aim of the current research is to propose a tentative approach to classification of online resources based on cross-cultural mediation competence aspects: mediation activities and strategies; to propose online classroom activities for synchronous and asynchronous learning.

\section{Results}

Media platforms provide language instructors with a powerful tool to boost communication and mediation skills of future mediators/translators/interpreters. In order to use them systematically we should understand what aim they can fulfil. According to CEFR [16], in cross-linguistic mediation, the learner acts as a social agent who creates bridges and helps to construct or convey meaning from one language to another. The focus is on the role of language in processes like creating the space and conditions for communicating and/or learning, collaborating to construct new meaning, encouraging others to construct or understand new meaning, and passing on new information in an appropriate form. The context can be social, pedagogic, cultural, linguistic or professional. Cross-linguistic mediation skills involve mediation activities (mediating texts, concepts and communication) and strategies (to explain a new concept, to simplify a text). A tentative approach to classification of information and communication technologies is proposed on the basis of mediation competence aspects (Table 1).

Table 1. Classification of online resources for mediation competence development.

\begin{tabular}{|l|l|l|}
\hline $\begin{array}{l}\text { Mediation } \\
\text { Competence Aspect }\end{array}$ & Online Resources & Possible activity \\
\hline & Mediation Activities & \\
\hline Mediating concepts & $\begin{array}{l}\text { MindMap (www.mindmup.com) } \\
\text { Creately } \\
\text { (https://creately.com/lp/concept-map- } \\
\text { maker) } \\
\text { Miro (https://miro.com) } \\
\text { MindMeister } \\
\text { (https://www.mindmeister.com) }\end{array}$ & $\begin{array}{l}\text { Cross-language } \\
\text { Concept mapping }\end{array}$ \\
\hline Mediating texts & $\begin{array}{l}\text { WordPress (www.wordpress.com); } \\
\text { Blogger (www.blogger.com) } \\
\text { Wonderopolis (https://wonderopolis.org) }\end{array}$ & Freewriting \\
\hline Mediating & SDG & Academy \\
\hline
\end{tabular}




\begin{tabular}{|l|l|l|}
\hline communication & $\begin{array}{l}\text { (https://sdgacademylibrary.mediaspace.k } \\
\text { altura.com) }\end{array}$ & $\begin{array}{l}\text { Participatory Learning } \\
\text { in Action (PLA) } \\
\text { Facebook (www.facebook.com) } \\
\text { Twitter (https://twitter.com) } \\
\text { Instagram (https://www.instagram.com) } \\
\text { session }\end{array}$ \\
\hline $\begin{array}{l}\text { Explaining a new } \\
\text { concept }\end{array}$ & $\begin{array}{l}\text { Kediation Strategies } \\
\text { Kahoot (https://kahoot.com) } \\
\text { Google Forms (www.google.com/forms) } \\
\text { EDpuzzle (https://edpuzzle.com) }\end{array}$ & $\begin{array}{l}\text { Cross-language } \\
\text { Socratic questioning }\end{array}$ \\
\hline Simplifying a text & $\begin{array}{l}\text { YouTube (www.youtube.com) Academy } \\
\text { SDG Aibrary } \\
\text { (https://sdgacademylibrary.mediaspace.k } \\
\text { altura.com) } \\
\text { Wonderopolis (https://wonderopolis.org) }\end{array}$ & Think, pair and share \\
\hline
\end{tabular}

The choice of learning activities is another issue to challenge remote learning. Possible activities have been proposed to foster cross-language mediation skills (Table 2). They aim at developing mediation skills and strategies alongside cultivating a digital mindset of a future translator.

Table 2. Activities aimed at developing mediation competence.

\begin{tabular}{|l|l|}
\hline Activity & Description \\
\hline Fross-language & $\begin{array}{l}\text { Freewriting can be a valuable tool to use with students. They } \\
\text { are asked to choose an aspect from a text or video in L1 that } \\
\text { they would like to comment upon in L2, and write for five } \\
\text { minutes. They should not stop writing within the stipulated } \\
\text { time limit. Then students read what they have written and } \\
\text { begin to analyze which ideas are worth keeping and which are } \\
\text { not. } \\
\text { Mode: asynchronous, online/offline }\end{array}$ \\
\hline $\begin{array}{l}\text { Cross-language } \\
\text { Concept mapping }\end{array}$ & $\begin{array}{l}\text { Concept maps are used to organize and represent knowledge. } \\
\text { They help students to explicitly integrate new and old } \\
\text { knowledge, to illustrate the relationships between different } \\
\text { concepts or processes and to communicate complex ideas } \\
\text { clearly. Students map concepts in L1 and L2, compare them to } \\
\text { find differences and similarities. } \\
\text { Mode: asynchronous, online/offline }\end{array}$ \\
\hline $\begin{array}{l}\text { Cross-language } \\
\text { in Action (PLA) }\end{array}$ & $\begin{array}{l}\text { PLA techniques encourage links between students' individual } \\
\text { worlds and activities related with a subject; they encourage } \\
\text { information exchange; and they have the ability to define } \\
\text { personal learning paths. Group objectives are set in L1 and L2. } \\
\text { They depend on the web source. Multicultural action groups } \\
\text { have to communicate in order to achieve group objectives in } \\
\text { L1 and L2 alternately. } \\
\text { Mode: synchronous, online/offline }\end{array}$ \\
\hline $\begin{array}{l}\text { Cross-language } \\
\text { session }\end{array}$ & $\begin{array}{l}\text { Participants work in buzz groups in L1 and L2 alternately to } \\
\text { discuss one aspect of a problem. Within each group, every } \\
\text { student contributes thoughts and ideas. Everyone should learn } \\
\text { from each other's input and experiences. In the end each buzz } \\
\text { group reports to the whole class. The whole class then makes a }\end{array}$ \\
\hline
\end{tabular}




\begin{tabular}{|l|l|}
\hline & $\begin{array}{l}\text { decision about the problem. } \\
\text { Mode: synchronous, online/offline }\end{array}$ \\
\hline $\begin{array}{l}\text { Sross-language } \\
\text { Socratic questioning }\end{array}$ & $\begin{array}{l}\text { Socratic questioning aims at helping students to construct } \\
\text { knowledge transforming them into skilled communicators with } \\
\text { a critical attitude towards knowledge. First a problem is } \\
\text { communicated in L1, and then questions are asked in L2 to } \\
\text { specify clarity, accuracy, precision, relevance, depth, breadth, } \\
\text { logic, significance. } \\
\text { Mode: asynchronous/ synchronous, online/offline }\end{array}$ \\
\hline Think, pair and share & $\begin{array}{l}\text { This activity helps to make a summary, stimulate critical } \\
\text { thinking or share responses, feelings and ideas. First, students } \\
\text { listen to or read about the topic assigned on their own in } \\
\text { L1/L2. Then they pair up with a partner for a further 5-10 } \\
\text { minutes to share their ideas with one another and discuss them } \\
\text { in another language L2/L1. } \\
\text { Mode: synchronous, online/offline }\end{array}$ \\
\hline
\end{tabular}

The proposed set of activities can be successfully broadened and levelled up. The teacher can follow the academic plan or tailor the material up to the students' needs, likes and wishes. A media fragment can be transformed into a teaching-learning tool and be recommended for online classroom work or challenging self-study to form some new communication experience landscape.

\section{Discussion and Conclusion}

There is an increasing need for the language professionals who are able to be mediators while communicating. The EU's experience proves the language-culture mediation is a vital tool for providing social interaction among individuals of different culture roots. Some researchers underline the fact that language awareness is "a bridge between school subjects and, in wider society, between people of different backgrounds and languages" [15]. To continue the metaphoric description, we can say that cross-language mediation skills create a network of bridges connecting cultures. Translator or interpreter professional training requires simultaneous development of L2 communicative competence as well as translation and interpretation competence. The current research looks at implementing this via including cross-language mediation skills development into language education provided either in an ordinary classroom or remotely. Mediation competence description offered by CEFR was employed to look at possible online resources and lesson activities. The study proposed a tentative approach to classification of web-resources based on cross-cultural mediation competence aspects: mediation activities and strategies. The most important limitation lies in the fact that our research only focuses on mediation skills development. Consequently this study has gone some way towards enhancing our understanding of how to efficiently categorise the multiplicity of online resources for the aims of teaching crossculture mediation. Further questions arise regarding online resources and activities aimed at translation competence development. These topics are deferred to future work

\section{References}

1. L. Alekseeva, I. Svyatchenko, G. Zvereva, Educational Media Resources as a Means of Forming a New Content of Regional History in the Light of the Problem of Teachers' 
Readiness to Profess It to High School Students. Mediaobrazovanie-Media Education, 2, 194-206 (2019)

2. A. Beeby, M. Fernández, O. Fox, A. Albir, I. Kozlova, A. Kuznik, W. Neunzig, P. Rodríguez, L. Romero, S. Wimmer, Results of the validation of the PACTE translation competence model: Acceptability and decision making. Across Languages and Cultures, 10(2), 207-230 (2009)

3. C. Cabalin, L. Montero, C. Cardenas, Media discourses about education: the case of standardized tests in Chile. Cuadernos Info, 44, 135-154 (2019)

4. Common European Framework of Reference for Languages: Learning, Teaching, Assessment Companion Volume with New Descriptors. Council of Europe (2018)

5. J. Corner, Origins and transformations: histories of communication study. Media culture \& society, 41(5), 727-737 (2019)

6. E.R. Davis, R. Wilson, "Not so globalised": contrasting media discourses on education and competitiveness in four countries. Journal of Asia Business Studies, 13(1), 151172 (2019)

7. Distance learning solutions. Global Education Coalition, https://en.unesco.org/covid19/educationresponse/solutions, last accessed 2021/03/03

8. R. Manssel, The Mediation of Hope: Communication Technologies and Inequality in Perspective. International Journal of Communication, 11, 4285-4304 (2017)

9. S. Mihelj, J. Stanyer, Theorizing media, communication and social change: towards a processual approach. Media Culture \& Society, 41(4), 482-501 (2019)

10. G. Motteram, Introduction. The range of technologies. In: Motteram G. (ed.). Innovations in Learning Technologies for English Language Teaching, $7-12$ (London, British Council, 2013)

11. J.C. Plantin, A. Punathambekar, Digital media infrastructures: pipes, platforms, and politics. Media Culture \& Society, 41(2), 163-174 (2019)

12. M. C. Pop, Stratégies pédagogiques de la traduction spécialisée en filière LEA: Le projet en classe de traduction technique. Litera, 30(1), 45 - 62 (2020) https://doi.org/10.26650/LITERA2020-0030

13. C. Salinas, A. Lozano, Mapping and recontextualizing the evolution of the term Latinx: An environmental scanning in higher education. Journal Of Latinos And Education, 18(4), 302-315 (2019)

14. T. Sarda, S. Natale, N. Sotirakopoulos, M. Monaghan, Understanding online anonymity. Media Culture \& Society, 41(4), 557-564 (2019)

15. A.M-L. Svalberg, Language Awareness research: where we are now. Language awareness, 25(1-2), 4-16 (2016)

16. Union of Translators of Russia Homepape https://rutrans.org, last accessed 2021/03/03

17. W. Willems, 'The politics of things': digital media, urban space, and the materiality of publics. Media Culture \& Society, 41(8), 1192-1209 (2019) 